\title{
Embryonal carcinoma of developing embryos of grass shrimp Palaemon orientis (Crustacea: Decapoda)
}

\author{
D. V. Lightner ${ }^{1}$, R. P. Hedrick ${ }^{2}$ \\ ${ }^{1}$ Environmental Research Laboratory, University of Arizona, 2601 East Airport Drive, Tucson, Arizona 85706, USA \\ ${ }^{2}$ Department of Medicine, School of Veterinary Medicine, University of California, Davis, California 95616, USA
}

\begin{abstract}
Approximately $20 \%$ of developing embryos on the pleopods of 3 brooding female grass shrimp Palaemon (Exopalaemon) orientis Holthuis (Crustacea: Decapoda), collected from a penaeid shrimp culture facility in Taiwan, were found by histologic examination to possess lesions with neoplastic characteristics. Affected embryos displayed marked disorganization of embryonic tissues, and possessed undifferentiated, primitive, pleomorphic cells that typically had hypertrophied nuclei with one or more prominent nucleoli. Cell division in the affected embryos was common, with bipolar, tripolar, and bizarre multipolar mitotic figures present in many of the neoplastic lesions. Because the lesions were undifferentiated and presumably originated prior to gastrulation from ectoderm progenitors, the neoplastic lesions are considered to be an embryonal carcinoma.
\end{abstract}

\section{INTRODUCTION}

The numbers of reports in the literature suggest that neoplasia is relatively uncommon in some invertebrate phyla, while in other groups such as the bivalve molluscs, it occurs frequently (Sparks 1985). There are more than 100 reports of tumor-like conditions in insects, probably the most studied members of the phylum Arthropoda, and several of these tumors are considered to be malignant neoplasms (Gateff 1969, 1986). Sparks (1985), in his review of the literature to that date, discussed only 5 tumor-like lesions in the Crustacea, none of which possessed characteristics of malignant neoplasia. Recently, however, there have been 2 reports of probable malignant neoplasia in decapod crustaceans (Lightner \& Brock 1987, Sparks \& Morado 1987), which suggest that such neoplastic lesions in crustaceans may be more common than previously supposed.

Described here are neoplastic lesions in developing embryos of the grass shrimp Palaemon orientis, present on the pleopods of brooding females collected from concrete rearing tanks of a penaeid shrimp culture facility in Taiwan. This new example of yet another crustacean neoplasm adds to the growing number of invertebrate neoplasms.

\section{MATERIALS AND METHODS}

Five adult grass shrimp, classified as Palaemon (Exopalaemon) orientis Holthuis (Crustacea: Decapoda), were collected in March 1986 from a 15000 l concrete rearing tank at the Tungkang Marine Laboratory, Pingtung, Taiwan, and preserved in Davidson's AFA fixative (Humason 1967) for later histological study. The tank contained a population of penaeid shrimp Penaeus vannamei which were being grown to adults in low density for possible use as future brood stock. The grass shrimp, which were not stocked there, had apparently entered the tank as postlarvae with the incoming seawater supply. The grass shrimp adults ranged from 0.1 to $1 \mathrm{~g}$ in weight. The 3 brooding females weighed approximately $1 \mathrm{~g}$ each, while an immature female and a male were about $0.1 \mathrm{~g}$ in weight.

Routine histological procedures were used. Following fixation in Davidson's AFA for $24 \mathrm{~h}$, the grass shrimp were transferred to $50 \%$ ethyl alcohol for storage and transport from Taiwan to the Tucson laboratory. The shrimp were then dehydrated through a graded alcohol series, cleared in Histo Clear (National Diagnostics, Somerville, New Jersey, USA), and embedded in Paraplast-Plus (Monoject Scientific, St. 
Louis, Missouri, USA). Sagittal sections of thickness 4 to $5 \mathrm{um}$ mounted on glass slides were stained with Mayer's hematoxylin and eosin (Luna 1968).

\section{RESULTS}

Three of the 5 shrimp examined were brooding females, with developing eggs attached to their pleopods (Fig. 1). All 3 females were found to possess embryos with neoplastic lesions. The incidence of neoplastic embryos among normal appearing embryos on the 3 females was 18 of 78,7 of 45 , and 5 of 25: an average incidence of about $20 \%$. Affected developing eggs were somewhat smaller than normally developing eggs (Fig. 2 \& 3), averaging $0.45 \pm 0.11 \mathrm{~mm}$ in length by $0.35 \pm 0.11 \mathrm{~mm}$ in width, while normal eggs were 0.52 \pm 0.12 and $0.40 \pm 0.13 \mathrm{~mm}$, respectively.

Affected embryos possessed generally disorganized tissues when compared to normal embryos of the same approximate age (Fig. 2 \& 3). Typical of normal developing embryos was the organization of embryonic tissues into the compound eyes, nerves and nerve cord, muscle, limb buds, gut, and other tissues around a centrally located yolk mass. Tissue organization in the neoplastic embryos was remarkably altered from that of the normal embryos. Except for the yolk mass and clefts in the tissue mass, marking the sites of limb buds. little recognizable organization of tissues was present in the affected embryos (Fig. $3 \& 4$ ). All parts of the developing embryo appeared equally affected.

In the affected embryos, neoplastic cells were undifferentiated, primitive, pleomorphic cells that possessed hypertrophied nuclei with one or more prominent nucleoli. Dividing cells were very common, displaying normal-type dipolar metaphase figures, but they also had numerous bizarre tripolar and multipolar metaphase figures (Fig. 4 to 6). Necrotic cells were present, although not abundant, in the affected embryos. Such cells were identified by their pyknotic or karyorrhectic nuclei (Fig. 4). Also present were a few cells with eosinophilic intranuclear Cowdry Type A inclusion bodies within hypertrophied nuclei (Fig. 6), which were suggestive of infection by the penaeid shrimp virus Infectious Hypodermal and Hematopoietic Necrosis Virus (IHHNV) (Lightner et al. 1983).

\section{DISCUSSION}

Brooding female decapod crustaceans, including grass shrimp, normally preen the developing eggs

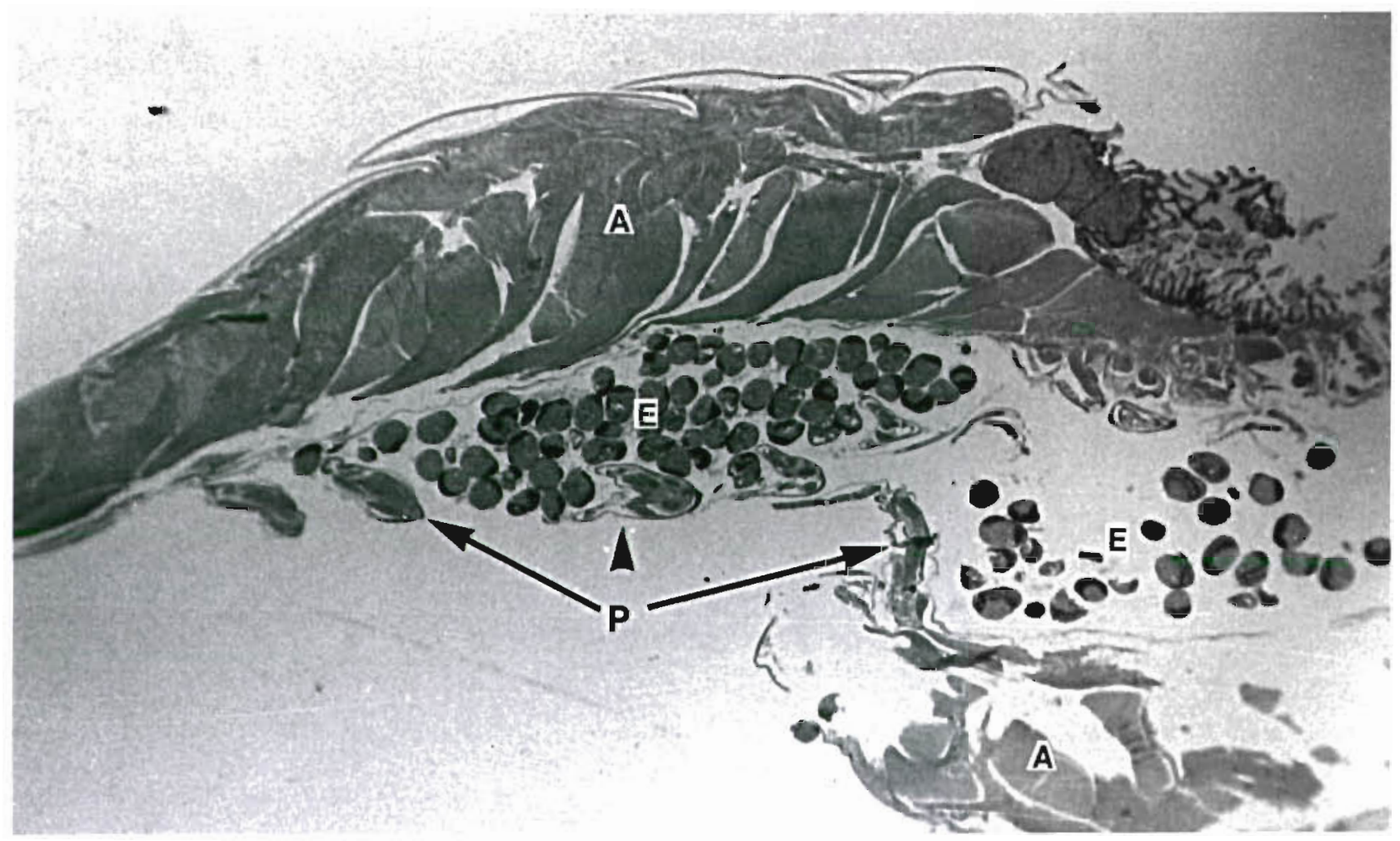

Fig. 1. Palaemon orientis. Mid-sagittal section of 2 brooding female grass shrimp. Developing embryos within the eggs (E) are visible attached to the pleopods $(\mathrm{P})$ under the abdomen $(\mathrm{A}) . \times 30$ 

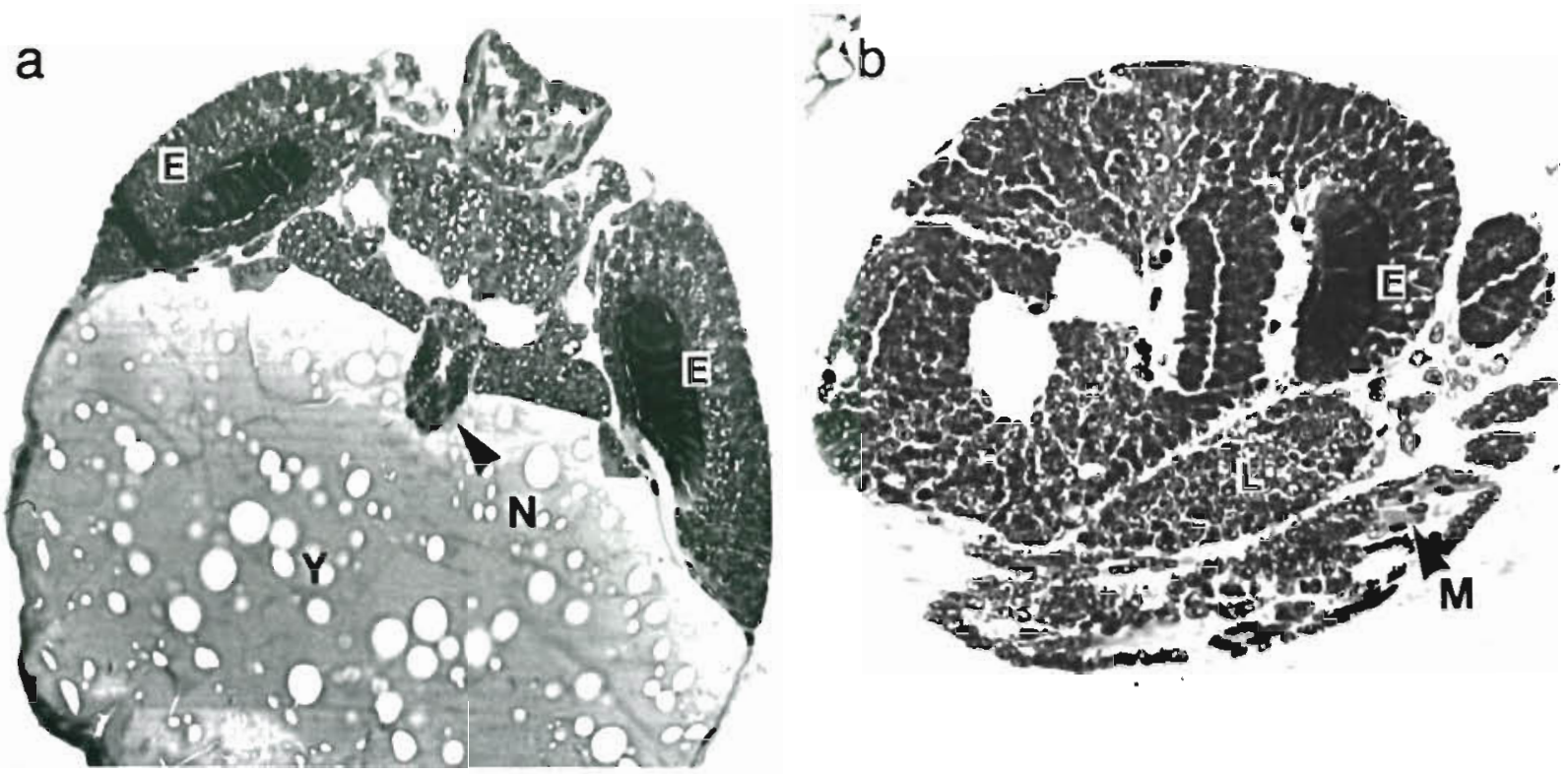

Fig. 2. Palaemon orientis. (a) Cross- and (b) sagittal sections through normal developing embryos. Organization of embryonic tissues into developing eyes (E), muscle (M), limb buds (L), nerve cord (N), and other tissues is shown around a central yolk $\operatorname{mass}(\mathrm{Y}) . \times 225$
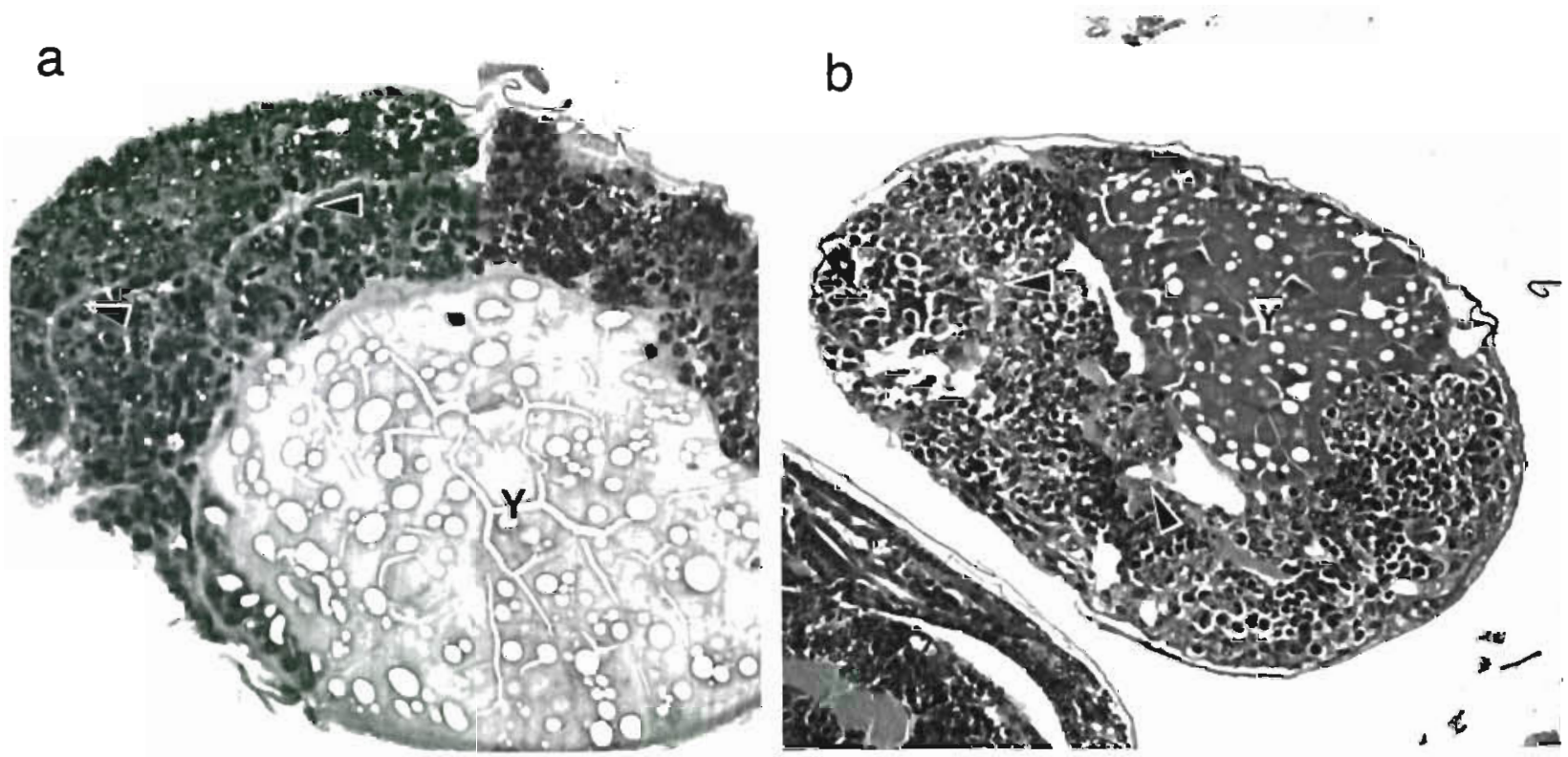

Fig. 3. Palaemon orientis. Embryos with neoplasic lesions classified as embryonal carcinomas. Tissue organization in the affected embryos has decreased compared to normal embryos. Except for the yolk mass (Y) and clefts (arrows) in the embryo, which mark the outline of limb buds, little tissue organization has remained apparent. (a) $\times 225$; (b) $\times 140$

attached to their pleopods, and detach and discard unfertilized eggs and dead embryos (Fisher \& Clark 1983). This behavior may explain why no embryos with advanced neoplastic lesions, or dead embryos with such lesions, were observed on the brooding females.

While no definite cause for the development of these lesions could be shown, the presence of the Cowdry
Type A intranuclear inclusion bodies in the neoplastic lesions in these embryos may be more than coincidence. These grass shrimp were incidentally collected from the same tank as were some sub-adult Penaeus vannamei, which were subsequently found to be infected by the penaeid virus IHHNV (Lightner et al. 1987). Cytopathology suggestive of IHHN virus infec- 


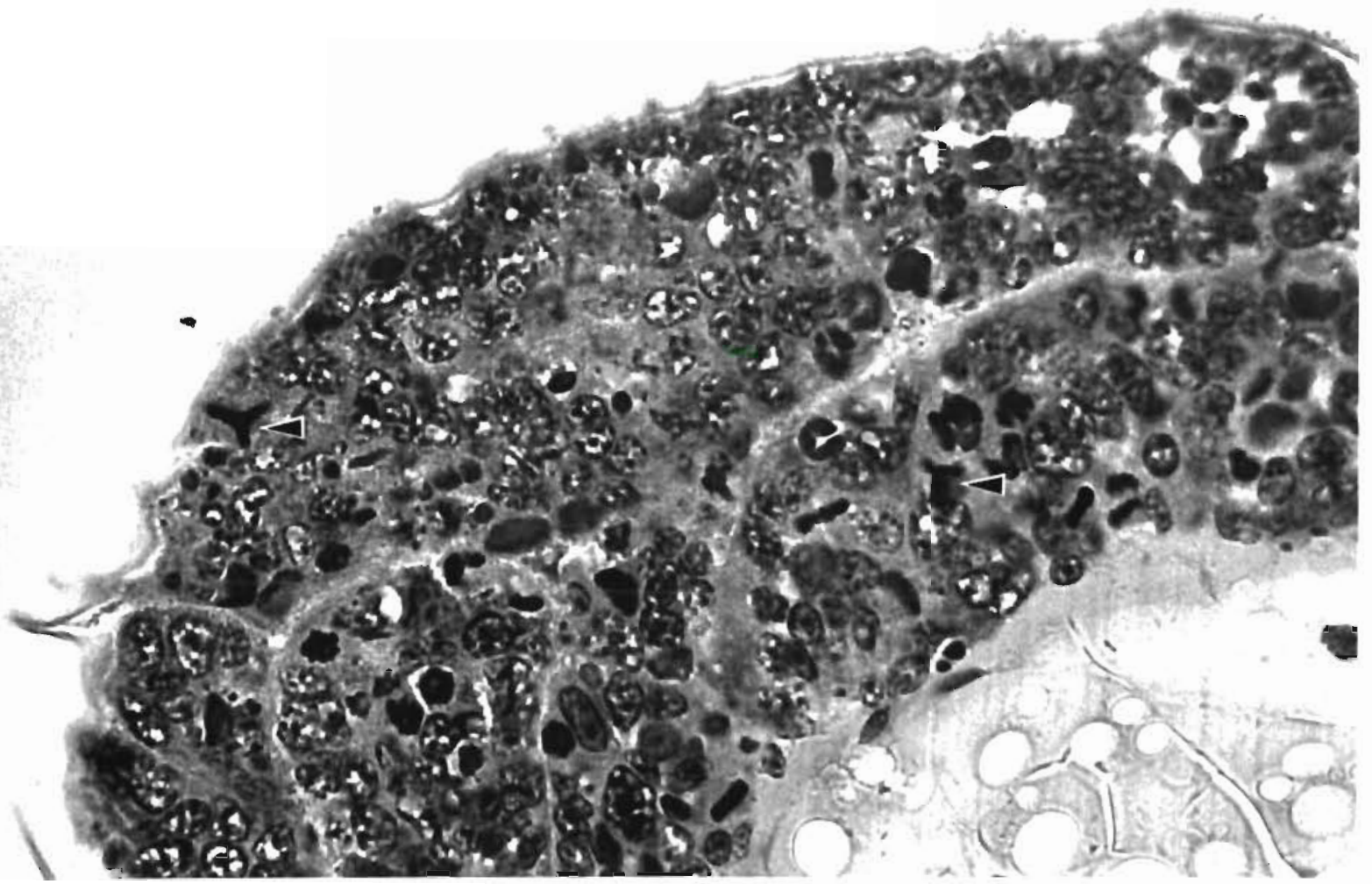

Fig. 4. Palaemon orientis. Higher magnification of the embryo shown in Fig. 3. At this magnification, details of the neoplastic changes are apparent. All parts of the embryo appear equally affected. Affected cells are undifferentiated, plemorphic, and primitive in appearance. They have hypertrophied nuclei, which possess one or more prominent nucleoli. Dividing cells are very common, some of which have bizarre metaphase figures (arrows). A few necrotic cells with pyknotic or karyorrhectic nuclei are also present. $\times 660$

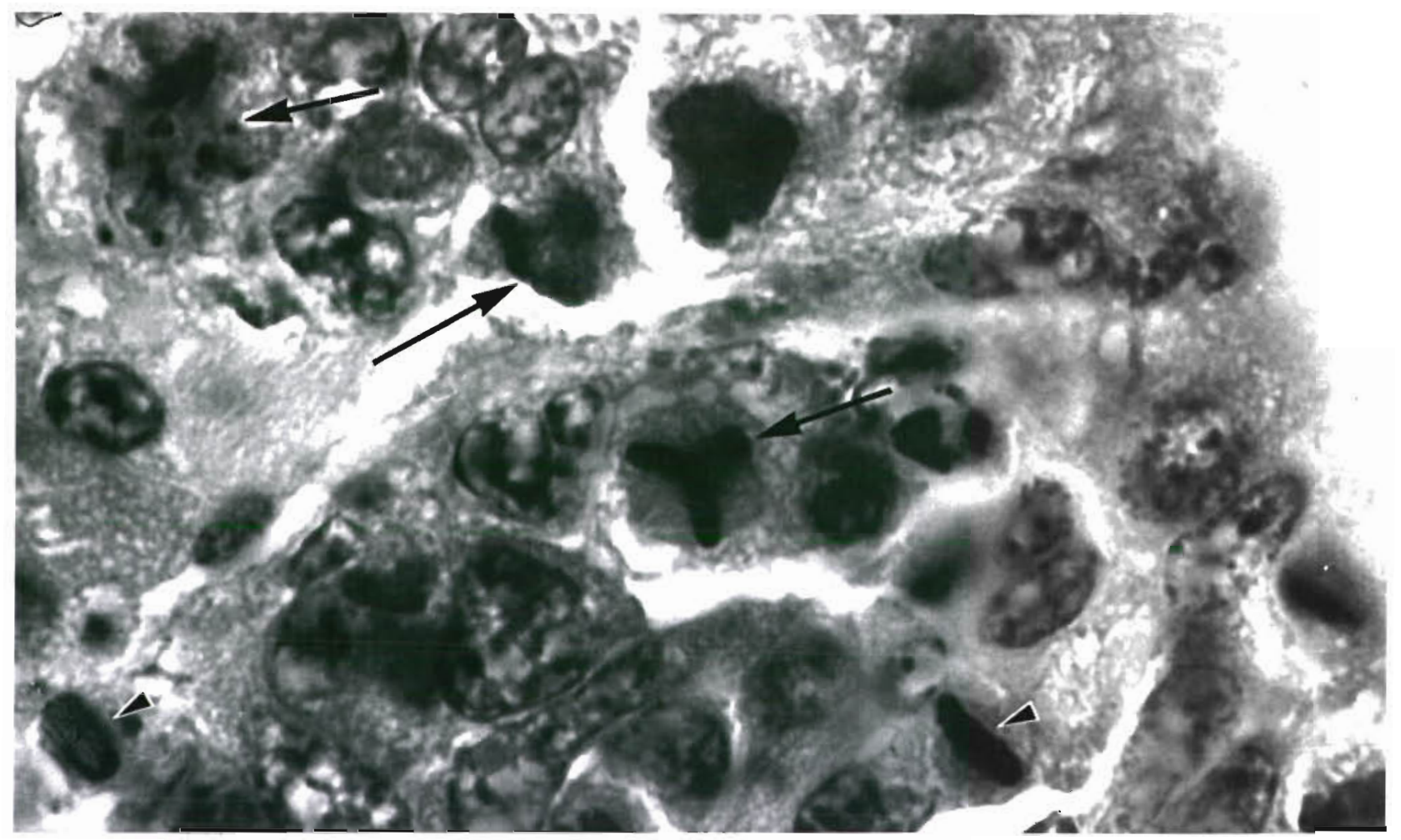

Fig. 5. Palaemon orientis. Higher magnification of examples of normal (small arrows) and bizarre mitotic figures (long arrows). $\times 1650$ 


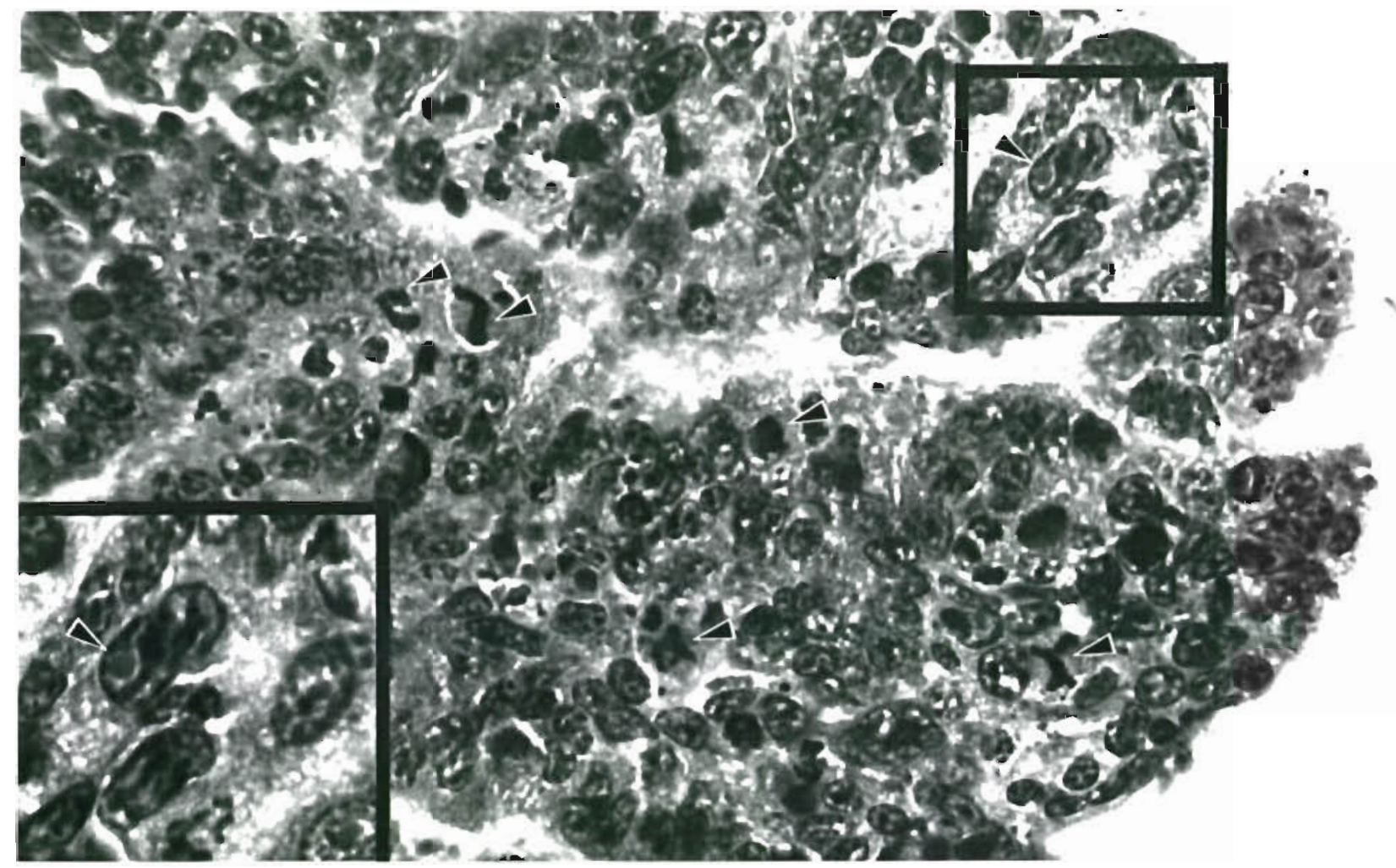

Fig. 6. Palaemon orientis. Another embryo with lesions of the embryonal carcinoma that show marked tissue disorganization, cells with hypertrophied nuclei, a high incidence of cell division, and the presence of numerous bizarre mitotic figures (arrows). Also shown in this embryo (arrow in inset) is a cell with a prominent intranuclear eosinophilic inclusion body of the Cowdry A type, which may suggest a virus infection. $\times 650$; inset $\times 1000$

tion was also found to be associated with a hematopoietic sarcoma in a cultured adult P. vannamei (Lightner \& Brock 1987). Despite this apparent association of IHHNV with neoplasia in shrimp, no cause and effect relationship of the virus to the tumors has been demonstrated. Attempts at our Tucson laboratory to induce neoplasia in developing embryos of the related grass shrimp, Palaemonetes pugio, by exposing cultured laboratory colonies of the shrimp to IHHNV continuously through 6 generations, have not produced embryos with neoplastic lesions (unpubl. obs.). Hence, other factors must be considered as possible causes of these neoplastic lesions.

Of interest were Hendricks' (1982) findings in teleost fishes that embryos are several orders of magnitude more sensitive than adults to chemical carcinogens. This phenomenon may explain why the developing embryos possessed neoplastic lesions, whereas the adults appeared normal and unaffected. Hence, the lesions could have started as a chemically induced mutation at the first or second cell stage in embryogenesis and then progressed, or the mutation could have occurred a little later in embryo development and the neoplastic cells may have subsequently replaced the normal cells present earlier.
Another interesting possibility is that the lesions could be the result of polyspermy. Boveri (1929) noted that polyspermic fertilization of sea urchin ova resulted in abnormal blastomeres. These abnormal blastomeres were formed from the unequal distribution of the genomic material between 2 or more daughter cells that were derived from a perturbed mitotic division. Boveri believed that these abnormal sea urchin ova resulting from polyspermy were neoplastic cells, and in such dividing cells Boveri described tripolar and multipolar mitotic spindles much like those shown in Fig. 4 to 6 .

The undifferentiated primitive, pleomorphic nature of the cells comprising the poorly organized tissue masses of the affected embryos described here, along with the uncontrolled division of embryonic cells, and the presence of bizarre and multipolar mitotic figures, support classification of the lesion in these embryos as an embryonal carcinoma. The occurrence of this neoplastic lesion in this order of invertebrates indicates the need for further investigation into the lesion's etiology and into the possibility that these animals could be an appropriate test species for evaluating environmental carcinogens, or possibly that they might serve as a model to test Boveri's (1929) theory that certain types of 
neoplastic change might result from polyspermy and other factors that result in perturbed mitotic division.

Acknowledgements. Technical assistance by R. M. Redman and W. C. Randall is thankfully acknowledged. Dr John Harshbarger (Registry of Tumors in Lower Animals, Smithsonian Institution, Washington, DC, USA) is thanked for his assistance in classifying the lesion and for his criticism of the manuscript. This work was partially supported by grants from the State of Hawaii Aquaculture Development Program and from Sea Grant of NOAA, U.S. Department of Commerce. Histological materials from these grass shrimp have been deposited at the Registry of Tumors in Lower Animals and assigned the acquisition numbers RTLA 3750 and 3751 .

\section{LITERATURE CITED}

Boveri, T (1929). The origin of malignant tumors. Williams \& Wilkins, Baltimore. (Translated from German by $M$. Boveri) Fisher, W. S., Clark, W. H., Jr. (1983). Eggs of Palaemon macrodactylus: I. Attachment to the pleopods and formation of the outer investment coat. Biol. Bull. mar. biol. Lab, Woods Hole 164: 189-200

Gateff, E. (1969). Neoplasms in mutant and cultured wild-type tissues of Drosophila. In: Dawe, C. J., Harsbarger, J. C. (ed.) A symposium on neoplasms and related disorders of invertebrate and lower vertebrate animals. National Cancer Institute Monograph 31, Bethesda, Maryland, p. 365-397
Gateff, E. (1986). Tumors in insects. In: Samson, R. A., Vak, J M., Peters, D. (ed.) Fundamental and applied aspects of invertebrate pathology. Foundation of the Fourth International Colloquium of Invertebrate Pathology, Wageningen, The Netherlands, p. 444-447

Hendricks, J. D. (1982). Chemical carcinogenesis in fish. In: Weber, L. J. (ed.) Aquatic toxicology. Raven Press, New York, p. 149-211

Humason, G. L. (1967). Animal tissue techniques. W. H. Freeman, San Francisco

Lightner, D. V., Redman, R. M., Bell, T. A. (1983). Infectious hypodermal and hematopoietic necrosis, a newly recognized virus disease of penaeid shrimp. J. Invertebr. Pathol. 42: $62-70$

Lightner, D. V., Brock, J. A. (1987). A lymphoma-like neoplasm arising from hematopoietic tissue in the white shrimp, Penaeus vannamei Boone (Crustacea: Decapoda). J. Invertebr. Pathol. 49: 188-193

Lightner, D. V., Hedrick, R. P., Fryer, J. L., Chen, S. N., Liao, I. C., Kou, G. H. (1987). A survey of cultured penaeid shrimp in Taiwan for viral and other important diseases. Fish Pathol. 22: 127-132

Luna, L.G. (ed.) (1968). Manual of histologic staining methods of the Armed Forces Institute of Pathology. McGraw Hill, New York

Sparks, A. K. (1985). Synopsis of invertebrate pathology exclusive of insects. Elsevier, New York

Sparks, A. K., Morado, J. F. (1987). A putative carcinoma-like neoplasm in the hindgut of the red king crab, Paralithodes camtschatica. J. Invertebr. Pathol. 50: 42-52 